\title{
BMJ Open Outdoor temperature and survival benefit of empiric potassium in users of furosemide in US Medicaid enrollees: a cohort study
}

\author{
Young Hee Nam, ${ }^{1}$ Warren B Bilker, ${ }^{1}$ Charles E Leonard, ${ }^{\oplus 1}$ Michelle L Bell, ${ }^{2}$ \\ Sean Hennessy ${ }^{1}$
}

To cite: Nam YH, Bilker WB, Leonard CE, et al. Outdoor temperature and survival benefit of empiric potassium in users of furosemide in US Medicaid enrollees: a cohort study. BMJ Open 2019;9:e023809. doi:10.1136/ bmjopen-2018-023809

- Prepublication history and additional material for this paper are available online. To view these files, please visit the journal online (http://dx.doi org/10.1136/bmjopen-2018023809).

Received 25 April 2018 Revised 10 December 2018 Accepted 27 December 2018

Check for updates

(C) Author(s) (or their employer(s)) 2019. Re-use permitted under CC BY-NC. No commercial re-use. See rights and permissions. Published by BMJ.

\section{${ }^{1}$ Center for}

Pharmacoepidemiology Research and Training, Center for Clinical Epidemiology and Biostatistics, Department of Biostatistics, Epidemiology and Informatics, Perelman of School of Medicine, University of Pennsylvania, Philadelphia, Pennsylvania, USA

${ }^{2}$ School of Forestry \&

Environmental Studies,

Yale University, New Haven, Connecticut, USA

Correspondence to

Dr Sean Hennessy;

hennessy@upenn.edu

\section{ABSTRACT}

Objective Heat is associated with elevated all-cause mortality, and furosemide-induced potassium depletion might be worsened by heat-induced sweating. Because empiric potassium is associated with a marked survival benefit in users of furosemide at a dose of $\geq 40 \mathrm{mg} /$ day, we hypothesised that this empiric potassium's survival benefit would increase with higher temperature $\left(\geq 24^{\circ} \mathrm{C}\right)$.

Design Cohort study.

Setting Outpatient setting, captured by Medicaid claims, supplemented with Medicare claims for dual enrollees, from 5 US states from 1999 to 2010 , linked to meteorological data.

Population/Participants Furosemide ( $\geq 40 \mathrm{mg} /$ day) initiators among adults continuously enrolled in Medicaid for at least 1 year prior to cohort entry (defined as the day following the dispensing day of each individual's first observed furosemide prescription).

Exposure Interaction between: (1) empiric potassium, dispensed the day of or the day following the dispensing of the initial furosemide prescription, and (2) daily average temperature and daily maximum temperature, examined separately.

Outcome All-cause mortality.

Results In 1:1 propensity score matched cohorts (total $\mathrm{n}=211878$ ) that included 89335 person-years and 9007 deaths, all-cause mortality rates per 1000 person-years were 96.0 (95\% Cl 93.2 to 98.9$)$ and 105.8 (95\% Cl 102.8 to 108.9 ) for potassium users and non-users, respectively. The adjusted OR of all-cause mortality for potassium use declined (ie, its apparent protective effect increased) as temperature increased, from a daily average temperature of about $28^{\circ} \mathrm{C}$ and a daily maximum temperature of about $31^{\circ} \mathrm{C}$. This relationship was not statistically significant with daily average temperature, but was statistically significant with daily maximum temperature ( $\mathrm{p}$ values for the interaction of potassium with daily maximum temperature and daily maximum temperature squared were 0.031 and 0.028 , respectively).

Conclusions The results suggest that empiric potassium's survival benefit among furosemide ( $\geq 40 \mathrm{mg} /$ day) initiators may increase as daily maximum temperature increases. If this relationship is real, use of empiric potassium in Medicaid enrollees initiating furosemide might be particularly important on hot days.
Strengths and limitations of this study

- This study used large-scale real-world data, representing about $40 \%$ of individuals in the US programme that covers nearly one in five Americans.

- It also used Zoning Improvement Plan code-level daily temperature data, which may reflect the outdoor temperature at each individual's place of residence more accurately than those based on larger geographic units.

- The study cohorts were well-balanced on measured baseline covariates even before matching, and this balance improved further with propensity score matching, which suggests that residual confounding may have played a limited role.

- Data on the degree to which subjects were actually exposed to outdoor temperatures were not available, although it seems unlikely that it differed substantially between potassium users and non-users among the matched furosemide users in the Medicaid population.

- Potassium users and non-users may have differed on unmeasured factors.

\section{INTRODUCTION}

High outdoor temperature is associated with increased all-cause mortality and other adverse outcomes including heat stroke, dehydration, renal failure, cardiovascular diseases, diabetes, electrolyte disorders and respiratory diseases. ${ }^{1-7}$ Older people and those with underlying health conditions or socioeconomic disadvantages are at particularly increased risk from heat exposure. ${ }^{2} 5$ 7-15 People who take furosemide, a potent and commonly used diuretic, might also be at increased risk, since furosemide leads to loss of potassium through the kidneys, ${ }^{16-18}$ which can increase mortality by mechanisms including cardiac arrhythmias. Heat could potentiate this risk because it leads to potassium loss through sweat. ${ }^{19}$ Although no randomised trials have investigated a survival 
benefit of empiric (ie, prophylactic or preventive) potassium use in furosemide users, a recent cohort study found that empiric potassium was associated with a relative survival benefit in initiators of furosemide, $7 \%$ at $<40 \mathrm{mg}$ / day and $16 \%$ at $\geq 40 \mathrm{mg} /$ day, respectively. ${ }^{20}$ We hypothesised that the survival benefit of empiric potassium in users of furosemide at a dose of $\geq 40 \mathrm{mg}$ /day would be more marked with higher outdoor temperature. Such a relationship would suggest that potassium administration in furosemide users may be particularly important when the outdoor temperature is high, which could have growing clinical and public health importance as global climate change continues, raising both the overall temperatures in general, and also the number and intensity of extremely hot days. ${ }^{21-23}$

\section{METHODS}

\section{Study design, population and data}

We conducted a propensity score matched cohort study among adult US Medicaid enrollees using (1) Medicaid claims from California, Florida, New York, Ohio and Pennsylvania from 1999 to 2010 supplemented with Medicare claims for the Medicaid-Medicare dual enrollees for the same period, including Part D Event Files from 2006 to 2010 (Part D began in 2006); and (2) meteorological data obtained from the US National Oceanic and Atmospheric Administration (NOAA) from 1999 to 2010. ${ }^{24}$ These five states include about $40 \%$ of the US Medicaid population. ${ }^{25}$ Adults ( $18 \leq$ age $<100$ years) who had continuous enrolment in Medicaid for at least 1 year before the cohort entry date (described below) were eligible for our analysis.

\section{Study cohort, exposure and outcome of interest and follow-up time}

The study cohort comprised apparent initiators of furosemide whose starting dose (calculated from the index prescription) was $40 \mathrm{mg} /$ day or higher. Apparent initiators of furosemide were defined as those in whom no furosemide was dispensed in the 365 days before cohort entry-the baseline period-based on a given furosemide prescription; such prescriptions are referred to as index furosemide prescriptions, and the date of their dispensing referred to as the index date. Individuals could enter the study only once. We excluded persons whose initial furosemide dose was greater than two times the daily recommended maximum dose of $600 \mathrm{mg} /$ day.

The exposure of interest was the interaction between (1) empiric potassium use, defined as a potassium prescription for an orally administered solid dosage form of a bicarbonate, chloride, citrate or gluconate salt that was dispensed on the index date or the next day, ${ }^{20}$ but not prior to the initial furosemide dispensing date, and (2) daily averge temperature and daily maximum temperature, examined separately. Expiric potassium use was defined in this way to better capture empiric potassium rather than potassium given as treatment for clinically recognised hypokalaemia. Although potassium products are available over the counter (OTC), such use is unlikely to have a large effect on study results because the strengths of OTC potassium (limited to less than about $2.5 \mathrm{mEq}$ of potassium, which is about $2 \%$ of the daily recommendation of potassium for adults) are considerably lower than typical doses of potassium used to prevent hypokalaemia (about $20 \mathrm{mEq} /$ day). Prescription drug use was identified by using National Drug Codes and days' supply on prescription claims. We allowed a 15-day gap between contiguous prescriptions and at the end of the last prescription to account for potential incomplete adherence.

The cohort entry date was the day following the index date for both potassium users and non-users, since we defined empiric potassium use as being dispensed a potassium prescription on the index date or the following day. We excluded patients who: (1) used non-solid dosage forms of furosemide or potassium, which might be indicative of inability to swallow a solid dosage form and/or functional impairments that may not be reliably ascertained in the administrative data; (2) had a diagnosis before the cohort entry date of hypokalaemia (International Classification of Diseases Ninth Revision Clinical Modification (ICD-9-CM): 276.8), hyperkalaemia (ICD-9-CM: 276.7) or acidosis (ICD-9-CM: 276.2), since hypokalaemia would suggest that in such persons, potassium was used for treatment rather than empirically, and hyperkalaemia and acidosis are contraindications for potassium; or (3) who, before the cohort entry date, were diagnosed with renal impairment or chronic kidney diseases (ICD-9-CM: $\left.582^{*}, 585^{*}, 586-587,588^{*}\right)$, received haemodialysis or peritoneal dialysis (ICD-9-CM: V56*; Current Procedural Terminology: 90918-90999), used potassium-sparing diuretics or who were dispensed potassium before the index date. Online supplementary figure S1 presents the sample size and how the inclusion and exclusion criteria were applied.

The outcome of interest was all-cause mortality, ascertained by linkage to the US Social Security Administration Death Master File.

Follow-up time (see online supplementary figure S2) began on the cohort entry date and ended with the first of the following events: (1) death; (2) end of days' supply of furosemide (following a 15-day grace period); (3) Medicaid enrolment discontinuation; or (4) end of the data set, that is, 31 December 2010. We did not censor follow-up time based on initiation or discontinuation of potassium in either the potassium user or non-user group because we wished to examine the temperature dependence of the survival benefit of the strategy of providing versus not providing empiric potassium, regardless of whether potassium was later discontinued or added.

\section{Meteorological data}

NOAA's meteorological data provide weather parameters, including daily minimum and maximum temperatures measured at weather stations, and the locations 
of these stations. For each furosemide user in our study cohort, we linked Zoning Improvement Plan code (ZIP code) of residence (ascertained from claims data) to the population-weighted centroid of that ZIP code area, which was estimated by using ZIP code boundaries, census block group boundaries and 2010 census block group-level population data. Individuals who had missing or invalid ZIP code of residence were excluded. Each population-weighted centroid of ZIP code was linked to the ZIP code-level, daily maximum temperature and daily average temperature (calculated as the arithmetic mean of the daily minimum and daily maximum temperatures). These ZIP code-level, daily outdoor temperatures were estimated by using day-level meteorological data, locations of weather stations and a spline interpolation method that is a commonly used geospatial analysis method to estimate properties, such as temperature, at unsampled sites based on the data of sampled sites, which may enable more precise estimation than a simple averaging method. ${ }^{26-28}$

\section{STATISTICAL ANALYSIS}

\section{Propensity score matching for balancing on potential} confounders

We used propensity score matching to balance the potassium and no-potassium groups on measured baseline factors. ${ }^{29}{ }^{30}$ First, we estimated each subject's propensity score by fitting a logistic regression model where the binary dependent variable was the receipt of empiric potassium and the independent variables (selected based on potential association with both potassium use and death; presented in table 1) included: (1) demographic characteristics (eg, age, sex, race, MedicaidMedicare dual eligibility, state of residence, etc); (2) diseases (eg, hypertension, lipid metabolism disorders, diabetes mellitus, ischaemic heart diseases, heart failure/ cardiomyopathy, asthma/chronic obstructive pulmonary disease/emphysema, etc); (3) prescription drugs (eg, renin-angiotensin-aldosterone system blockers, antihyperlipidaemic agents, beta blockers, calcium channel blockers, corticosteroids, antidiabetic agents, average daily dose of furosemide at cohort entry, etc); and (4) healthcare services utilisation intensity (including nursing home residence, number of inpatient hospitalisations, number of outpatient visits and number of prescription drug fillings). ${ }^{31}$ All independent variables were binary and assessed during the 1-year baseline period, except for the age and average daily dose of furosemide at cohort entry, continuous variables. We then used 1:1 nearest neighbour propensity score matching to match users of empiric potassium to non-users. ${ }^{32}$

\section{Baseline characteristics, incidence rates and logistic regression analysis}

We first calculated descriptive statistics on baseline characteristics (table 1) and compared the mortality rates between users and non-users of empiric potassium before and after propensity score matching. The balance in the baseline characteristics was assessed by standardised difference (ie, the mean difference of a variable between the two groups in units of the estimated common SD of that variable in the two groups), with a value exceeding 0.1 suggestive of potentially meaningful imbalance between groups. ${ }^{30}$ Next, we examined the temperature-potassium-mortality association in the high temperature range (defined as $\geq 24^{\circ} \mathrm{C}$ or $75^{\circ} \mathrm{F}$ ) by modelling the interaction between temperature (daily average temperature and daily maximum temperature, separately) and potassium exposure status on the log odds of mortality using a multivariable logistic regression model where the unit of observation was person-day, allowing temperature to vary by day for each individual. The $24^{\circ} \mathrm{C}$ minimum temperature was chosen in advance based on literature indicating a U-shaped or similar relationship between temperature and death, with a nadir between $22^{\circ} \mathrm{C}$ and $26^{\circ} \mathrm{C}$, although we recognise that this relationship varies by location. ${ }^{33-36}$ We excluded rare, extremely high temperatures (daily average temperature $>43^{\circ} \mathrm{C}$ or $110^{\circ} \mathrm{F}$; daily maximum temperature $>49^{\circ} \mathrm{C}$ or $120^{\circ} \mathrm{F}$ ). Given that the true functional form of the relationship between potassium use, temperature and mortality is unknown, we examined a model that included a linear term and a quadratic term of temperature and two temperature-potassium exposure interaction terms (hereinafter referred to as a quadratic model). This model is expressed as equation 1.

$$
\begin{aligned}
\operatorname{logit}\left(Y_{i j}\right)= & \alpha+\beta_{0}\left(T_{i j}\right)+\beta_{1}\left(T_{i j}^{2}\right)+\beta_{2}\left(K_{i}^{+}\right) \\
& +\beta_{3}\left(T_{i j} \times K_{i}^{+}\right)+\beta_{4}\left(T_{i j}^{2} \times K_{i}^{+}\right)+\gamma \mathbf{X}_{i}+\epsilon_{i j}
\end{aligned}
$$

In this equation, $Y_{i j}$ is an indicator variable for the death outcome of person $i$ on day $j$; $T_{i j}$ is the outdoor temperature for person $i$ at their ZIP code area on day $j ; K_{i}^{+}$is a binary variable indicating the potassium use or non-use of person $i$; and $\mathbf{X}_{i}$ is a vector of time-invariant covariates of person $i$ for which we used age group at cohort entry, sex and race group. We examined daily average temperature and daily maximum temperature in separate models. We also considered a strictly linear model, but decided to use a quadratic model to avoid reliance on the assumption that the relationship between temperature and mortality is linear. Because older adults are known to be more vulnerable to the heat-related mortality, we performed a subgroup analysis for older adults (age $\geq 65$ years). In addition, to examine whether our results from the propensity score matched cohort would have been influenced by other meteorological parameters, we performed a sensitivity analysis that additionally controlled for daily relative humidity at the person level. High humidity suppresses evaporation of sweat and sweat rate, ${ }^{37} 38$ thus might affect potassium loss as well as humans' ability to thermoregulate, possibly influencing mortality and potassium-mortality relationship.

Analyses were performed by using ArcGIS V.10.3 (Esri, Redlands, California, USA), SAS V.9.4 (SAS Institute, 
Table 1 Baseline characteristics of the unmatched and matched study cohorts

\begin{tabular}{|c|c|c|c|c|c|c|}
\hline & \multicolumn{3}{|c|}{ Before PS matching } & \multicolumn{3}{|c|}{ After PS matching } \\
\hline & \multirow{2}{*}{$\begin{array}{l}\begin{array}{l}\text { Potassium } \\
\text { group }\end{array} \\
\mathrm{n}=106907\end{array}$} & \multirow{2}{*}{$\begin{array}{l}\text { No- } \\
\text { potassium } \\
\text { group } \\
\mathrm{n}=230948 \\
\end{array}$} & \multirow{2}{*}{$\begin{array}{l}\text { Standardised } \\
\text { difference }\end{array}$} & \multirow{2}{*}{$\begin{array}{l}\begin{array}{l}\text { Potassium } \\
\text { group }\end{array} \\
\mathrm{n}=105939\end{array}$} & \multirow{2}{*}{$\begin{array}{l}\text { No-potassium } \\
\text { group } \\
\mathrm{n}=105939\end{array}$} & \multirow{2}{*}{$\begin{array}{l}\text { Standardised } \\
\text { difference }\end{array}$} \\
\hline & & & & & & \\
\hline \multicolumn{7}{|l|}{ Sociodemographic characteristics } \\
\hline \multicolumn{7}{|l|}{ Age at cohort entry, in years (\%) } \\
\hline $35 \leq$ Age $<50$ & 15.03 & 14.94 & 0.00 & 15.04 & 15.15 & 0.00 \\
\hline $50 \leq$ Age $<65$ & 23.82 & 24.77 & 0.02 & 23.83 & 23.86 & 0.00 \\
\hline $65 \leq$ Age $<80$ & 34.78 & 33.75 & 0.02 & 34.77 & 34.97 & 0.00 \\
\hline $80 \leq \mathrm{Age}<100$ & 22.44 & 22.26 & 0.00 & 22.42 & 22.18 & 0.01 \\
\hline Black & 15.36 & 18.15 & 0.07 & 15.44 & 15.30 & 0.00 \\
\hline Hispanic & 15.58 & 14.03 & 0.04 & 15.63 & 15.65 & 0.00 \\
\hline Other/Unknown & 15.38 & 17.77 & 0.06 & 15.46 & 15.32 & 0.00 \\
\hline Medicaid-Medicare dual eligible (\%) & 70.36 & 67.43 & 0.06 & 70.20 & 70.21 & 0.00 \\
\hline \multicolumn{7}{|l|}{ State of residence (\%) } \\
\hline California & 45.89 & 40.73 & 0.10 & 46.28 & 46.52 & 0.00 \\
\hline Florida & 17.42 & 8.89 & 0.25 & 16.71 & 16.56 & 0.00 \\
\hline New York & 17.13 & 29.27 & 0.29 & 17.29 & 17.22 & 0.00 \\
\hline Ohio & 10.35 & 8.93 & 0.05 & 10.44 & 10.54 & 0.00 \\
\hline 2002 & 9.72 & 9.64 & 0.00 & 9.72 & 9.76 & 0.00 \\
\hline 2003 & 9.55 & 9.43 & 0.00 & 9.55 & 9.40 & 0.01 \\
\hline 2004 & 7.25 & 7.88 & 0.02 & 7.31 & 7.48 & 0.01 \\
\hline 2005 & 8.36 & 8.38 & 0.00 & 8.37 & 8.37 & 0.00 \\
\hline 2006 & 14.12 & 14.03 & 0.00 & 14.07 & 14.05 & 0.00 \\
\hline 2007 & 9.12 & 7.99 & 0.04 & 9.01 & 8.92 & 0.00 \\
\hline 2008 & 7.03 & 6.66 & 0.01 & 7.07 & 6.92 & 0.01 \\
\hline 2009 & 7.89 & 7.49 & 0.02 & 7.87 & 7.78 & 0.00 \\
\hline 2010 & 8.18 & 8.26 & 0.00 & 8.18 & 8.09 & 0.00 \\
\hline \multicolumn{7}{|l|}{ Diseases } \\
\hline Alkalosis, metabolic (\%) & 0.20 & 0.20 & 0.00 & 0.21 & 0.21 & 0.00 \\
\hline Amyloidosis (\%) & 0.03 & 0.04 & 0.01 & 0.03 & 0.02 & 0.01 \\
\hline Anaemia (\%) & 29.31 & 27.46 & 0.04 & 29.19 & 29.22 & 0.00 \\
\hline Ascites (\%) & 1.26 & 1.40 & 0.01 & 1.26 & 1.29 & 0.00 \\
\hline Asthma/COPD/emphysema (\%) & 31.41 & 27.43 & 0.09 & 31.12 & 31.13 & 0.00 \\
\hline $\begin{array}{l}\text { Cardiac dysrhythmias/conduction } \\
\text { disorder (\%) }\end{array}$ & 26.31 & 23.76 & 0.06 & 26.10 & 26.18 & 0.00 \\
\hline Cerebrovascular disease (\%) & 18.45 & 17.54 & 0.02 & 18.39 & 18.52 & 0.00 \\
\hline
\end{tabular}


Table 1 Continued

\begin{tabular}{|c|c|c|c|c|c|c|}
\hline & \multicolumn{3}{|c|}{ Before PS matching } & \multicolumn{3}{|c|}{ After PS matching } \\
\hline & \multirow{2}{*}{$\begin{array}{l}\begin{array}{l}\text { Potassium } \\
\text { group }\end{array} \\
\mathrm{n}=106907\end{array}$} & \multirow{2}{*}{$\begin{array}{l}\text { No- } \\
\text { potassium } \\
\text { group } \\
\mathrm{n}=230948\end{array}$} & \multirow{2}{*}{$\begin{array}{l}\text { Standardised } \\
\text { difference }\end{array}$} & \multirow{2}{*}{$\begin{array}{l}\begin{array}{l}\text { Potassium } \\
\text { group }\end{array} \\
\mathrm{n}=105939\end{array}$} & \multirow{2}{*}{$\begin{array}{l}\begin{array}{l}\text { No-potassium } \\
\text { group }\end{array} \\
\mathrm{n}=105939\end{array}$} & \multirow{2}{*}{$\begin{array}{l}\text { Standardised } \\
\text { difference }\end{array}$} \\
\hline & & & & & & \\
\hline Diabetes insipidus (\%) & 0.06 & 0.06 & 0.00 & 0.06 & 0.05 & 0.00 \\
\hline Diabetes mellitus (\%) & 38.90 & 39.70 & 0.02 & 38.95 & 38.93 & 0.00 \\
\hline Oedema (\%) & 23.65 & 19.87 & 0.09 & 23.42 & 23.56 & 0.00 \\
\hline Glaucoma (\%) & 9.55 & 9.84 & 0.01 & 9.54 & 9.49 & 0.00 \\
\hline Heart failure/cardiomyopathy (\%) & 36.48 & 32.96 & 0.07 & 36.21 & 36.25 & 0.00 \\
\hline HIV/AIDS (\%) & 0.45 & 0.69 & 0.03 & 0.45 & 0.46 & 0.00 \\
\hline Hyperosmolality (\%) & 0.46 & 0.59 & 0.02 & 0.47 & 0.47 & 0.00 \\
\hline Hypertensive disease (\%) & 66.66 & 64.48 & 0.05 & 66.50 & 66.58 & 0.00 \\
\hline Hyperthyroidism (\%) & 2.25 & 1.96 & 0.02 & 2.24 & 2.18 & 0.00 \\
\hline Hypothyroidism (\%) & 16.21 & 14.53 & 0.05 & 16.09 & 16.19 & 0.00 \\
\hline Ischaemic heart disease (\%) & 36.52 & 32.89 & 0.08 & 36.22 & 36.39 & 0.00 \\
\hline Kidney disease† (\%) & 9.27 & 10.60 & 0.04 & 9.32 & 9.24 & 0.00 \\
\hline Lipid metabolism disorder (\%) & 43.21 & 37.95 & 0.11 & 42.88 & 43.07 & 0.00 \\
\hline Liver disease (\%) & 20.13 & 19.54 & 0.01 & 20.08 & 20.10 & 0.00 \\
\hline $\begin{array}{l}\text { Magnesium metabolism disorder } \\
\text { (\%) }\end{array}$ & 0.63 & 0.62 & 0.00 & 0.63 & 0.67 & 0.00 \\
\hline Nocturia (\%) & 1.37 & 1.20 & 0.02 & 1.36 & 1.31 & 0.00 \\
\hline Pulmonary circulation disease (\%) & 5.00 & 4.40 & 0.03 & 4.93 & 4.93 & 0.00 \\
\hline $\begin{array}{l}\text { Pulmonary congestion and } \\
\text { hypostasis/pulmonary oedema (\%) }\end{array}$ & 6.47 & 5.89 & 0.02 & 6.44 & 6.45 & 0.00 \\
\hline Pyloric stenosis (\%) & 0.07 & 0.08 & 0.00 & 0.07 & 0.07 & 0.00 \\
\hline $\begin{array}{l}\text { Rheumatoid arthritis and other } \\
\text { inflammatory polyarthropathies (\%) }\end{array}$ & 5.16 & 4.64 & 0.02 & 5.15 & 5.13 & 0.00 \\
\hline Systemic lupus erythematosus (\%) & 0.70 & 0.67 & 0.00 & 0.68 & 0.68 & 0.00 \\
\hline Urinary obstruction (\%) & 0.41 & 0.40 & 0.00 & 0.41 & 0.41 & 0.00 \\
\hline \multicolumn{7}{|l|}{ Prescription drugs } \\
\hline RAAS blockers (\%) & 52.01 & 54.35 & 0.05 & 52.14 & 52.01 & 0.00 \\
\hline Adrenergic agents (\%) & 11.99 & 12.29 & 0.01 & 12.03 & 12.03 & 0.00 \\
\hline Antiarrhythmics (\%) & 3.59 & 2.62 & 0.06 & 3.51 & 3.63 & 0.01 \\
\hline Antidiabetic agents (\%) & 31.61 & 34.30 & 0.06 & 31.75 & 31.67 & 0.00 \\
\hline Antiglaucoma agents (\%) & 19.45 & 18.51 & 0.02 & 19.38 & 19.31 & 0.00 \\
\hline Antihyperlipidaemic agents (\%) & 39.67 & 38.39 & 0.03 & 39.59 & 39.54 & 0.00 \\
\hline Antiobesity agents (\%) & 0.18 & 0.11 & 0.02 & 0.17 & 0.17 & 0.00 \\
\hline Antiretrovirals (\%) & 0.74 & 1.14 & 0.04 & 0.75 & 0.76 & 0.00 \\
\hline Beta blockers, systemic (\%) & 34.20 & 33.88 & 0.01 & 34.11 & 34.02 & 0.00 \\
\hline Bisphosphonates (\%) & 2.95 & 2.43 & 0.03 & 2.91 & 2.91 & 0.00 \\
\hline Calcium channel blockers (\%) & 31.14 & 31.70 & 0.01 & 31.15 & 30.94 & 0.00 \\
\hline Corticosteroids, systemic (\%) & 30.55 & 28.13 & 0.05 & 30.37 & 30.44 & 0.00 \\
\hline Digoxin (\%) & 9.95 & 8.89 & 0.04 & 9.86 & 10.01 & 0.01 \\
\hline Diuretics, thiazides (\%) & 13.82 & 15.37 & 0.04 & 13.88 & 13.66 & 0.01 \\
\hline Immunosuppressives (\%) & 0.64 & 0.76 & 0.01 & 0.64 & 0.62 & 0.00 \\
\hline Thyroid hormones (\%) & 12.24 & 11.66 & 0.02 & 12.19 & 12.31 & 0.00 \\
\hline
\end{tabular}

Continued 


\begin{tabular}{|c|c|c|c|c|c|c|}
\hline & \multicolumn{3}{|c|}{ Before PS matching } & \multicolumn{3}{|c|}{ After PS matching } \\
\hline & \multirow{2}{*}{$\begin{array}{l}\begin{array}{l}\text { Potassium } \\
\text { group }\end{array} \\
n=106907\end{array}$} & \multirow{2}{*}{$\begin{array}{l}\text { No- } \\
\text { potassium } \\
\text { group } \\
\mathrm{n}=230948\end{array}$} & \multirow{2}{*}{$\begin{array}{l}\text { Standardised } \\
\text { difference }\end{array}$} & \multirow{2}{*}{$\begin{array}{l}\begin{array}{l}\text { Potassium } \\
\text { group }\end{array} \\
\mathrm{n}=105939\end{array}$} & \multirow{2}{*}{$\begin{array}{l}\text { No-potassium } \\
\text { group } \\
n=105939\end{array}$} & \multirow{2}{*}{$\begin{array}{l}\text { Standardised } \\
\text { difference }\end{array}$} \\
\hline & & & & & & \\
\hline Vasodilators (\%) & 10.41 & 10.47 & 0.00 & 10.40 & 10.48 & 0.00 \\
\hline $\begin{array}{l}\text { Average daily dose of furosemide at } \\
\text { cohort entry } \neq \geq 80 \mathrm{mg} / \text { day }(\%)\end{array}$ & 17.80 & 18.16 & 0.01 & 17.79 & 17.79 & 0.00 \\
\hline \multicolumn{7}{|l|}{ Healthcare services utilisation intensity } \\
\hline Nursing home residence (\%) & 16.37 & 18.04 & 0.04 & 16.40 & 16.38 & 0.00 \\
\hline $\begin{array}{l}\text { Prescription drug fillings, mean } \\
\text { number }\end{array}$ & 25.71 & 24.73 & 0.05 & 25.66 & 25.74 & 0.00 \\
\hline
\end{tabular}

*Urban residence: ascertained by the ZIP codes in the claims data used and ZIP Code to Carrier Locality File from the Centres for Medicare and Medicaid Services (Centers for Medicare and Medicaid Services, 2017).

†Kidney disease: kidney diseases, except for chronic kidney diseases or renal impairment.

$\ddagger$ Average daily dose of furosemide at cohort entry: excluded persons whose initial furosemide dose was greater than two times daily recommended maximum dose of $600 \mathrm{mg} / \mathrm{day}$.

COPD, chronic obstructive pulmonary disease; PS, propensity score; RAAS, renin-angiotensin-aldosterone system; Ref, reference.

Cary, North Carolina, USA), and Stata V.14 (StataCorp, College Station, Texas, USA).

\section{Ethical approval}

This study was approved by the institutional review board of the University of Pennsylvania, which waived the requirement for obtaining informed consent. We attest that we have obtained appropriate permissions and paid any required fees for use of copyright-protected materials.

\section{Patient and public involvement}

Patients and public were not involved in planning or conducting this study.

\section{RESULTS}

Online supplementary figure S1 shows the number of potentially eligible and included/excluded subjects, with reasons for exclusion. Prior to matching, there were 337885 eligible initiators of furosemide $\geq 40 \mathrm{mg}$ / day, 106907 (32\%) of whom were empiric potassium users. Nearly all of the empiric potassium users were pair-matched to a non-user, resulting in 211878 subjects (105939 subjects in each group) that included 89335 person-years and 9007 deaths. In the matched potassium cohort, $76 \%$ of the follow-up time was covered by an active prescription for potassium (follow-up continued as long as the furosemide prescription was active; see online supplementary figure S2), while only $12 \%$ of the follow-up time for the no-potassium group was covered by an active prescription for potassium; $85 \%$ of individuals in the no-potassium group had no-potassium prescriptions during follow-up. As shown in table 1, baseline variables were reasonably well balanced even before matching, and this balance was improved by propensity score matching. In the matched cohorts, median follow-up time was 69 days in potassium users and 65 days in potassium non-users, and the mortality rate (in deaths per 1000 person-years) was 96.0 (95\% CI 93.2 to 98.9 ) in users and 105.8 (95\% CI 102.8 to 108.9 ) in non-users, which corresponds to number needed to treat of 102 (95\% CI 64 to 256) over a 1-year period, that is, 102 (95\% CI 64 to 256) furosemide ( $\geq 40 \mathrm{mg} /$ day) initiators would need to be treated with empiric potassium for the prevention of one additional death over a 1-year period.

Table 2 examines the associations between empiric potassium use and mortality as (1) a function of daily average temperature and daily average temperature squared and (2) a function of daily maximum temperature and daily maximum temperature squared, as well as the interaction between these temperature metrics and potassium use (daily average temperature and daily maximum temperature examined separately). Because daily maximum temperature exceeded $24^{\circ} \mathrm{C}$ more often than did daily average temperature, there were more observations for daily maximum temperature. As seen in figures 1 and 2, the OR of all-cause mortality 


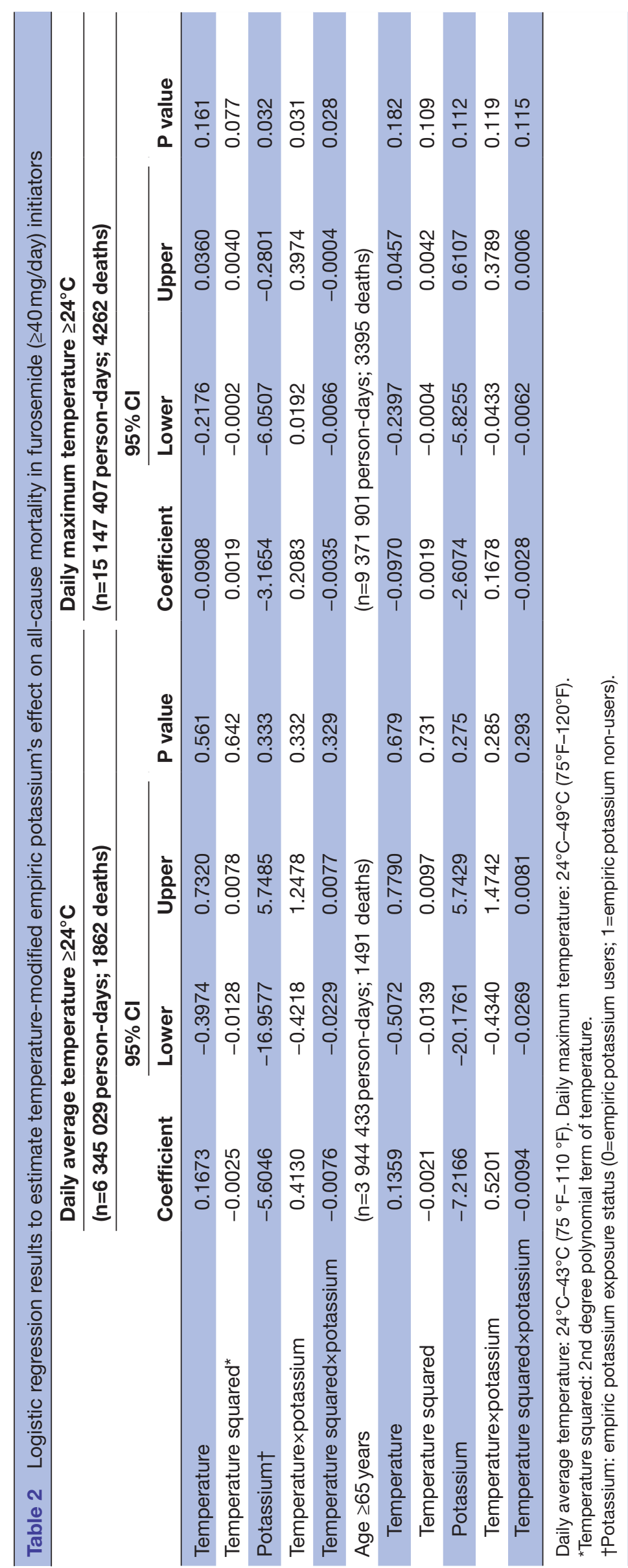


A. All individuals in the study cohort

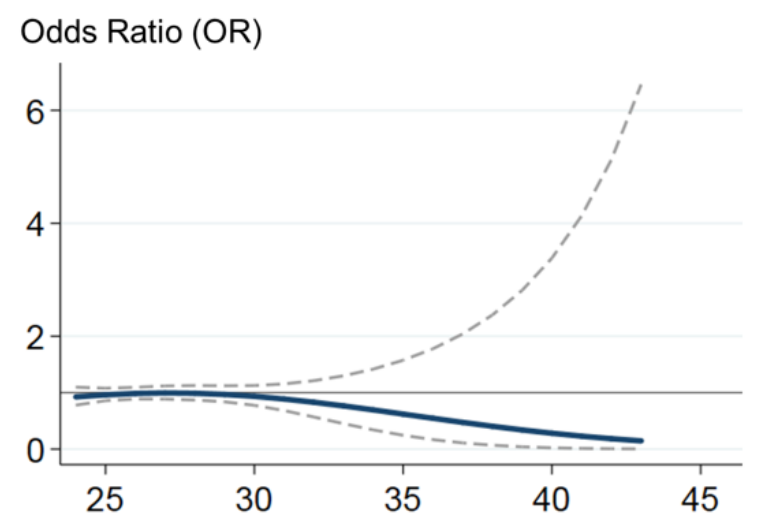

Daily Average Temperature $\left({ }^{\circ} \mathrm{C}\right)$

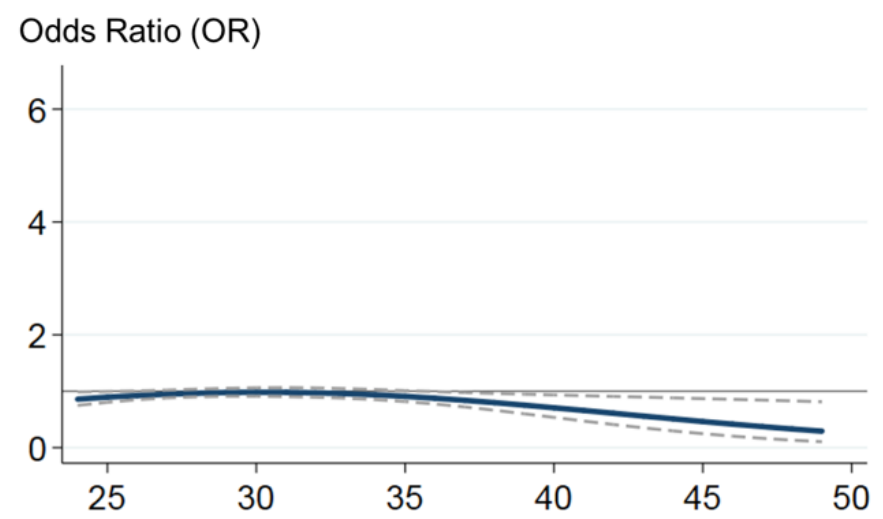

Daily Maximum Temperature $\left({ }^{\circ} \mathrm{C}\right)$

B. Older individuals in the study cohort (age $\geq 65$ years)

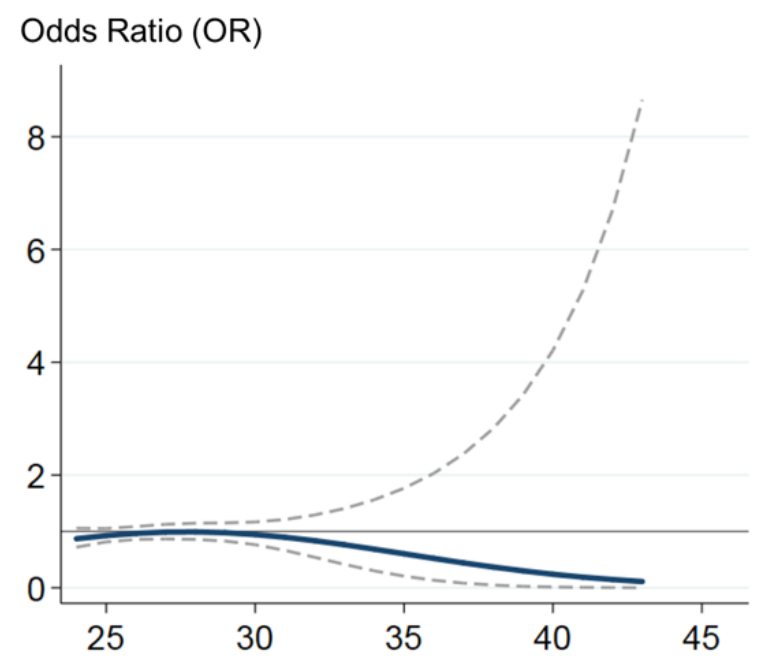

Daily Average Temperature $\left({ }^{\circ} \mathrm{C}\right)$

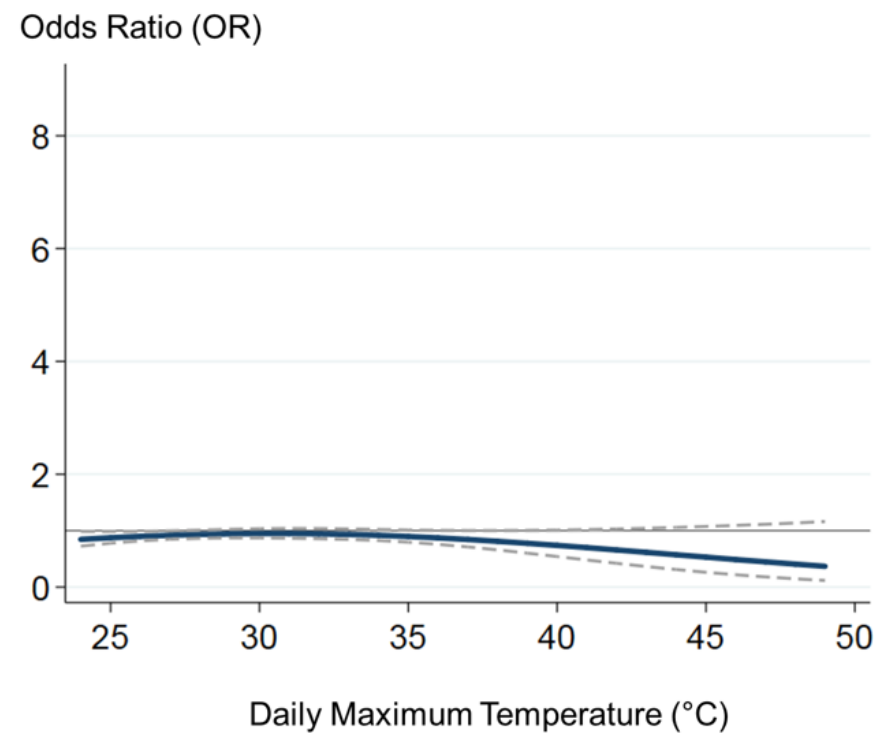

Figure $1 \mathrm{OR}$ and $95 \% \mathrm{Cl}$ of all-cause mortality for empiric potassium use versus non-use by temperature. Daily average temperature: $24^{\circ} \mathrm{C}-43^{\circ} \mathrm{C}\left(75^{\circ} \mathrm{F}-110^{\circ} \mathrm{F}\right)$. Daily maximum temperature: $24^{\circ} \mathrm{C}-49^{\circ} \mathrm{C}\left(75^{\circ} \mathrm{F}-120^{\circ} \mathrm{F}\right)$. Bold solid lines indicate OR, and thin dash lines indicate $95 \% \mathrm{Cl}$.

for potassium use (calculated from regression results) appeared to be lower (ie, its protective effect appeared to increase) when temperature was higher for both temperature metrics. The $\mathrm{p}$ values for the interaction terms of potassium were not statistically significant with daily average temperature (interaction with daily average temperature, $\mathrm{p}=0.332$; and with daily average temperature squared, $\mathrm{p}=0.329)$, but were statistically significant with daily maximum temperature (interaction with daily maximum temperature, $\mathrm{p}=0.031$; and with daily maximum temperature squared, $\mathrm{p}=0.028$ ) (table 2 ). The estimated association corresponds to approximately a $6 \%$ point reduction in the odds for each $1^{\circ} \mathrm{C}$ increase in daily average temperature between $28^{\circ} \mathrm{C}$ and $43^{\circ} \mathrm{C}$, and a $4 \%$ point reduction in the odds for each $1^{\circ} \mathrm{C}$ increase in daily maximum temperature between $31^{\circ} \mathrm{C}$ and $49^{\circ} \mathrm{C}$.
The results for older adults showed similar patterns, but the CI were larger. In the sensitivity analysis that additionally controlled for daily relative humidity, the results were similar, and the $p$ values for the interaction terms of potassium with daily maximum temperature were statistically significant (interaction with daily maximum temperature, $\mathrm{p}=0.028$; and with daily maximum temperature squared, $\mathrm{p}=0.025)$ (table 3 ).

\section{DISCUSSION}

This study examined whether the survival benefit of empiric potassium in users of furosemide ( $\geq 40 \mathrm{mg} /$ day) increases with higher daily average temperature and daily maximum temperature. Consistent with earlier findings in the same population using 1999-2007 data, ${ }^{20}$ empiric 

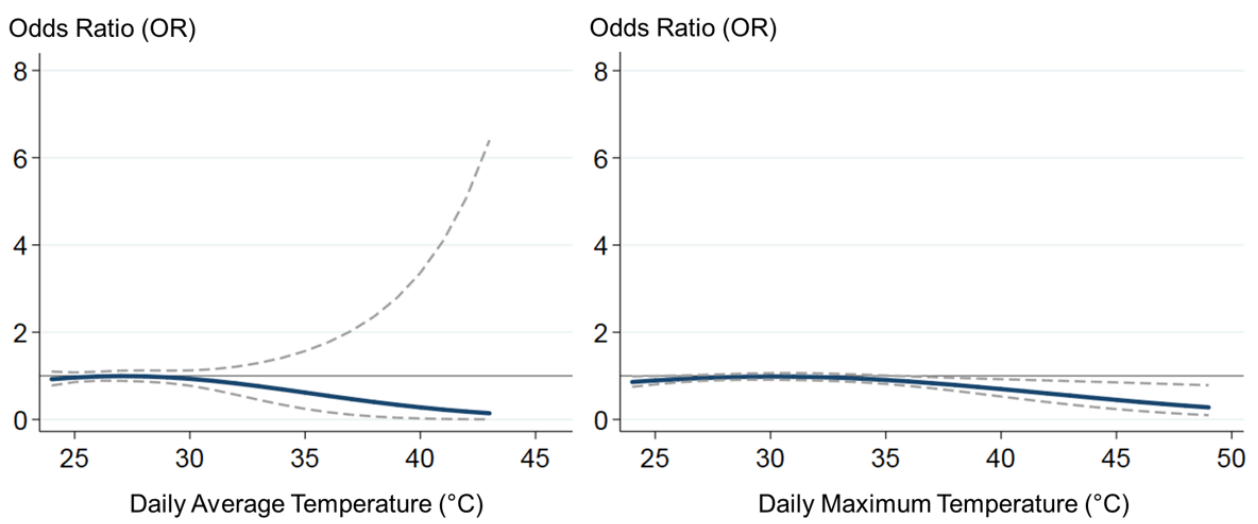

Figure 2 OR and $95 \% \mathrm{Cl}$ of all-cause mortality for empiric potassium use versus non-use by temperature, additionally controlling for daily relative humidity. Daily average temperature: $24^{\circ} \mathrm{C}-43^{\circ} \mathrm{C}\left(75^{\circ} \mathrm{F}-110^{\circ} \mathrm{F}\right)$. Daily maximum temperature: $24^{\circ} \mathrm{C}-49^{\circ} \mathrm{C}\left(75^{\circ} \mathrm{F}-120^{\circ} \mathrm{F}\right)$. Bold solid lines indicate OR, and thin dash lines indicate $95 \% \mathrm{Cl}$.

potassium use was associated with a survival benefit in furosemide $(\geq 40 \mathrm{mg} /$ day $)$ initiators. The results suggest that this survival benefit may increase as daily maximum temperature increases. This relationship was statistically significant in the primary analysis and the sensitivity analysis that adjusted for daily relative humidity.

If this potential relationship between temperature and the survival benefit of empiric potassium is true, it would have important clinical and public health implications. It is well established that high outdoor temperature is associated with increase in mortality and morbidity. ${ }^{39-43}$ Some excess deaths in furosemide users, especially among socioeconomically disadvantaged populations such as Medicaid enrollees in the USA, might be avoidable through interventions to increase potassium intake on hot days. The number of lives saved by such interventions would be expected to increase as global climate change continues. ${ }^{21-23}$

One might hypothesise seasonality in the association between temperature and mortality, or that individuals residing in warmer regions might tolerate increases in temperature better than those in cooler regions. Also, a temperature-potassium interaction on mortality, if it exists, might differ across subgroups, such as geographic regions, sociodemographic characteristics including age, comorbidities or degree of frailty. Because we were unable to explore such relationships given the limited number of high-temperature deaths, further research is warranted to investigate these potential relationships in diverse subgroups and health outcomes. In addition, future studies will need to investigate other functional forms or metrics of temperature, including lagged effects of heat, cumulative days of high temperature and variation from the mean temperature at a given location.

This study has several strengths. First, it used large-scale real-world data, representing about $40 \%$ of individuals in the US Medicaid programme that covers nearly one in five Americans. It also used ZIP code-level daily temperature data, which may better reflect the outdoor temperature at each individual's place of residence than temperature

Table 3 Logistic regression results to estimate temperature-modified empiric potassium's effect on all-cause mortality in furosemide ( $\geq 40 \mathrm{mg} /$ day) initiators, additionally controlling for daily relative humidity

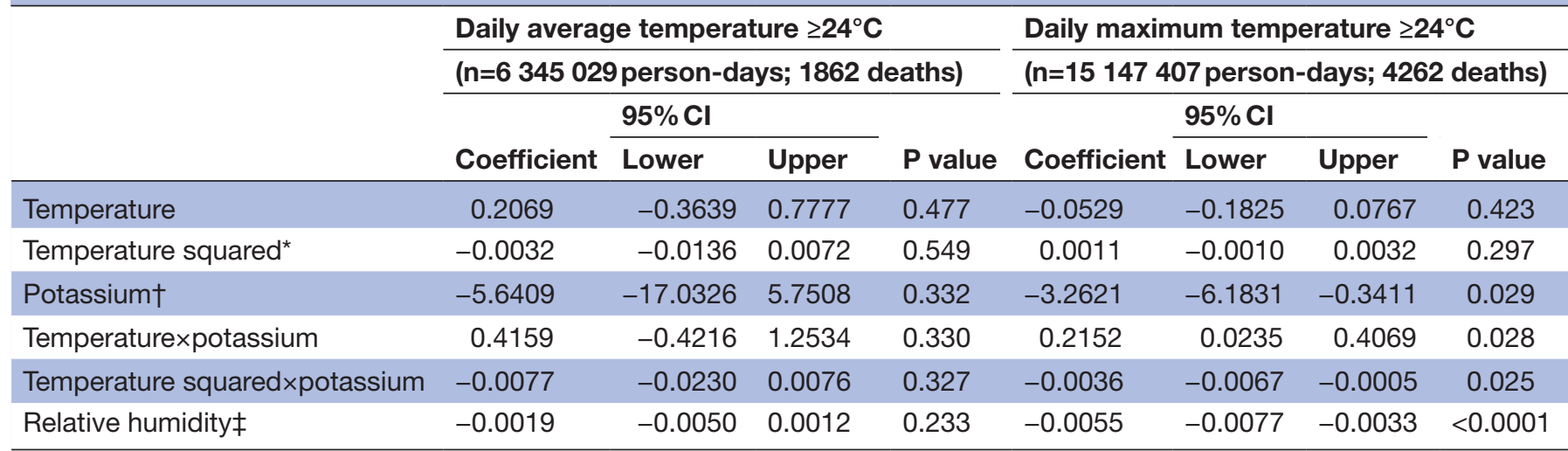

Daily average temperature: $24^{\circ} \mathrm{C}-43^{\circ} \mathrm{C}\left(75^{\circ} \mathrm{F}-110^{\circ} \mathrm{F}\right)$. Daily maximum temperature: $24^{\circ} \mathrm{C}-49^{\circ} \mathrm{C}\left(75^{\circ} \mathrm{F}-120^{\circ} \mathrm{F}\right)$.

${ }^{\star}$ Temperature squared: second degree polynomial term of temperature.

†Potassium: empiric potassium exposure status ( $0=$ empiric potassium users; $1=$ =empiric potassium non-users).

$\ddagger$ Relative humidity: daily relative humidity. 
over larger geographic areas. Further, the study cohorts had good balance in the measured baseline covariates even before matching, and this balance improved further with propensity score matching, which suggests a limited role for potential confounding factors.

This study also has limitations. First, we did not have data on individuals' use of air conditioning or the amount of time spent outdoors. Therefore, we do not know the degree to which subjects were actually exposed to outdoor temperatures. However, because all individuals in our study were enrolled in Medicaid, a public health insurance programme for socioeconomically disadvantaged individuals who meet certain low socioeconomic status criteria, it seems unlikely that the access to air conditioning is substantially different between users and non-users of empiric potassium who were matched on clinical variables. Prior studies that also lacked such data found associations between temperature and of a variety of health endpoints. ${ }^{39} 4042$ Therefore, it seems likely that any potential bias introduced by lack of data on air conditioning would have been toward the null. Second, results observed in US Medicaid enrollees, who have lower incomes and poorer health in general than other groups, might not be generalisable to other populations. Nevertheless, about $20 \%$ of the US population is enrolled in Medicaid; thus, this is an important population in its own right as well as from the public health and health policy perspectives. Third, although our study cohorts showed good balance in measured covariates, we cannot rule out the possibility of imbalances in unobserved factors. Finally, our study did not examine location-specific differences in the estimated associations, which may differ due to variation in the relationship between temperature and health.

\section{CONCLUSIONS}

The results suggest that empiric potassium's survival benefit may increase as daily maximum temperature increases in Medicaid enrollees who initiate furosemide ( $\geq 40 \mathrm{mg} /$ day). This potential relationship should be confirmed in independent data sets. Given the widespread use of furosemide, interventions based on this relationship might be able to benefit many people worldwide, especially those socioeconomically more vulnerable and living in high-temperature areas.

Acknowledgements The authors are grateful to Ms Qing Liu and Ms Min Du of the Center for Clinical Epidemiology and Biostatistics, University of Pennsylvania, for their assistance with biostatistics computer programming.

Contributors SH, CEL and WBB conceived and designed the study. SH and CEL were involved in acquisition of data. YHN and WBB performed statistical analysis. YHN, WBB, CEL, MLB and SH interpreted the results. YHN drafted the manuscript. YHN, WBB, CEL, MLB and SH critically revised the manuscript for important intellectual content. All authors approved the final manuscript to be submitted for publication and the authorship list.

Funding This work was supported by the US National Institute on Aging (Grant number: R01AG025152) and the US National Institute of Diabetes and Digestive and Kidney Diseases (Grant number: R01DK102694).
Disclaimer The US National Institute on Aging and the US National Institute of Diabetes and Digestive and Kidney Diseases had no role in the design and conduct of the study, data collection and analysis, interpretation of the results, writing and review of the manuscript or the decision to submit the manuscript for publication.

Competing interests None declared.

Patient consent for publication Not required.

Ethics approval Institutional review board of the University of Pennsylvania.

Provenance and peer review Not commissioned; externally peer reviewed.

Data sharing statement No additional data available. The original US Medicaid and Medicare claims are third party data and available to obtain under a data use agreement from the Centers for Medicare \& Medicaid Services (CMS) (https://www. cms.gov/). The authors did not have any special access privileges that others would not have. The procedures to obtain access to these data are described in the CMS website (https://www.cms.gov/Research-Statistics-Data-and-Systems/Research/ ResearchGenInfo/ResearchDataAssistanceCenter.html) and the Research Data Assistance Center (ResDAC) website (https://www.resdac.org/cms-data/request/ cms-data-request-center)

Open access This is an open access article distributed in accordance with the Creative Commons Attribution Non Commercial (CC BY-NC 4.0) license, which permits others to distribute, remix, adapt, build upon this work non-commercially, and license their derivative works on different terms, provided the original work is properly cited, appropriate credit is given, any changes made indicated, and the use is non-commercial. See: http://creativecommons.org/licenses/by-nc/4.0/.

\section{REFERENCES}

1. Green RS, Basu R, Malig B, et al. The effect of temperature on hospital admissions in nine California counties. Int J Public Health 2010;55:113-21.

2. Lin S, Luo M, Walker RJ, et al. Extreme high temperatures and hospital admissions for respiratory and cardiovascular diseases. Epidemiology 2009;20:738-46.

3. Bobb JF, Obermeyer Z, Wang Y, et al. Cause-specific risk of hospital admission related to extreme heat in older adults. JAMA 2014;312:2659-67.

4. Gasparrini A, Armstrong B. The impact of heat waves on mortality. Epidemiology 2011;22:68-73.

5. Hajat S, Armstrong B, Baccini M, et al. Impact of high temperatures on mortality: is there an added heat wave effect? Epidemiology 2006;17:632-8.

6. Fletcher BA, Lin S, Fitzgerald EF, et al. Association of summer temperatures with hospital admissions for renal diseases in New York State: a case-crossover study. Am J Epidemiol 2012;175:907-16.

7. Knowlton K, Rotkin-Ellman M, King G, et al. The 2006 California heat wave: impacts on hospitalizations and emergency department visits. Environ Health Perspect 2009;117:61-7.

8. Anderson GB, Bell ML. Heat waves in the United States: mortality risk during heat waves and effect modification by heat wave characteristics in 43 U.S. communities. Environ Health Perspect 2011;119:210-8.

9. Semenza JC, McCullough JE, Flanders WD, et al. Excess hospital admissions during the July 1995 heat wave in Chicago. Am J Prev Med 1999;16:269-77.

10. Anderson GB, Dominici F, Wang Y, et al. Heat-related emergency hospitalizations for respiratory diseases in the Medicare population. Am J Respir Crit Care Med 2013;187:1098-103.

11. Basu R. High ambient temperature and mortality: a review of epidemiologic studies from 2001 to 2008. Environ Health 2009;8:1-13.

12. Semenza JC, Rubin $\mathrm{CH}$, Falter $\mathrm{KH}$, et al. Heat-related deaths during the July 1995 heat wave in Chicago. N Engl J Med 1996;335:84-90.

13. Naughton MP, Henderson A, Mirabelli MC, et al. Heat-related mortality during a 1999 heat wave in Chicago. Am J Prev Med 2002;22:221-7.

14. Jones TS, Liang AP, Kilbourne EM, et al. Morbidity and mortality associated with the July 1980 heat wave in St Louis and Kansas City, Mo. JAMA 1982;247:3327-31.

15. Vanakoski J, Seppälä T. Heat exposure and drugs. A review of the effects of hyperthermia on pharmacokinetics. Clin Pharmacokinet 1998;34:311-22.

16. Holland OB, Nixon JV, Kuhnert L. Diuretic-induced ventricular ectopic activity. Am J Med 1981;70:762-8.

17. Sica DA. Diuretic-related side effects: development and treatment. $J$ Clin Hypertens 2004;6:532-40. 
18. MacMahon S, Collins G, Rautaharju P, et al. Electrocardiographic left ventricular hypertrophy and effects of antihypertensive drug therapy in hypertensive participants in the Multiple Risk Factor Intervention Trial. Am J Cardiol 1989;63:202-10.

19. Mao IF, Chen ML, Ko YC. Electrolyte loss in sweat and iodine deficiency in a hot environment. Arch Environ Health 2001;56:271-7.

20. Leonard CE, Razzaghi H, Freeman CP, et al. Empiric potassium supplementation and increased survival in users of loop diuretics. PLoS One 2014;9:e102279.

21. Melillo JM, Richmond TC, Yohe GW. Climate Change Impacts in the United States: The Third National Climate Assessment. Washington, D.C: U.S. Global Change Research Program, 2014:841pp. (Accessed 12 Aug 2016).

22. International Panel on Climate Change, et al. Climate Change 2013: The Physical Science Basis. In: Stocker TF, Qin D, Plattner GK, eds. Contribution of Working Group I to the Fifth Assessment Report of the Intergovernmental Panel on Climate Change. Cambridge, United Kingdom and New York, NY, USA: Cambridge University Press.

23. United States Environmental Protection Agency. Future of climate change. https://archive.epa.gov/epa/climate-change-science/futureclimate-change.html (Accessed 8 Jan 2018).

24. National Oceanic and Atmospheric Administration (NOAA). National Climatic Data Center. https://www.ncdc.noaa.gov/ (Accessed 9 May 2015).

25. Kaiser Family Foundation. Medicaid state fact sheets. https://www. kff.org/interactive/medicaid-state-fact-sheets/ (Accessed 12 Aug 2016).

26. Garnero G, Godone D. Comparisons between different interpolation techniques. ISPRS - International Archives of the Photogrammetry, Remote Sensing and Spatial Information Sciences 2013;XL-5/ W3:139-44.

27. Hartkamp AD, De Beurs K, Stein A, et al. Interpolation Techniques for Climate Variables. Mexico, D.F: CIMMYT, 1999. NRG-GIS Series 99-01.

28. Childs C. Interpolating surfaces in ArcGIS spatial analyst. ArcUser 2004;July-Sept:32-5.

29. Rosenbaum PR, Rubin DB. The central role of the propensity score in observational studies for causal effects. Biometrika 1983;70:41-55.

30. Austin PC. Goodness-of-fit diagnostics for the propensity score model when estimating treatment effects using covariate adjustment with the propensity score. Pharmacoepidemiol Drug Saf 2008;17:1202-17.

31. Schneeweiss S, Seeger JD, Maclure M, et al. Performance of comorbidity scores to control for confounding in epidemiologic studies using claims data. Am J Epidemiol 2001;154:854-64.

32. Austin PC. Some methods of propensity-score matching had superior performance to others: results of an empirical investigation and Monte Carlo simulations. Biom J 2009;51:171-84.

33. Sharovsky R, César LA, Ramires JA. Temperature, air pollution, and mortality from myocardial infarction in São Paulo, Brazil. Braz $J$ Med Biol Res 2004;37:1651-7.

34. Vaneckova P, Beggs PJ, de Dear RJ, et al. Effect of temperature on mortality during the six warmer months in Sydney, Australia, between 1993 and 2004. Environ Res 2008;108:361-9.

35. Newby DE. Triggering of acute myocardial infarction: beyond the vulnerable plaque. Heart 2010;96:1247-51.

36. Dilaveris P, Synetos A, Giannopoulos G, et al. CLimate Impacts on Myocardial infarction deaths in the Athens TErritory: the CLIMATE study. Heart 2006;92:1747-51.

37. Frye AJ, Kamon E. Sweating efficiency in acclimated men and women exercising in humid and dry heat. J Appl Physiol Respir Environ Exerc Physiol 1983;54:972-7.

38. Kenney WL, Anderson RK. Responses of older and younger women to exercise in dry and humid heat without fluid replacement. Med Sci Sports Exerc 1988;20:155-60.

39. Anderson BG, Bell ML. Weather-related mortality: how heat, cold, and heat waves affect mortality in the United States. Epidemiology 2009;20:205-13.

40. Hajat S, O'Connor M, Kosatsky T. Health effects of hot weather: from awareness of risk factors to effective health protection. Lancet 2010;375:856-63.

41. Basu R, Ostro BD. A multicounty analysis identifying the populations vulnerable to mortality associated with high ambient temperature in California. Am J Epidemiol 2008;168:632-7.

42. Medina-Ramón M, Zanobetti A, Cavanagh DP, et al. Extreme temperatures and mortality: assessing effect modification by personal characteristics and specific cause of death in a multi-city case-only analysis. Environ Health Perspect 2006;114:1331-6.

43. Basu R. High ambient temperature and mortality: a review of epidemiologic studies from 2001 to 2008. Environmental Health 2009;8:1-13. 